\title{
EKSPERYMENTALNA ANALIZA MODALNA DŹWIGARA KOMPOZYTOWEGO FRP Z KOMPOZYTOWĄ PEYTĄ POMOSTOWĄ
}

\begin{abstract}
Celem przeprowadzonych badań było ustalenie parametrów dynamicznych dźwigara kompozytowego z kompozytową płytą pomostową, tj. ustalenie częstotliwości drgań rezonansowych, postaci drgań i współczynników tłumienia. Zastosowana eksperymentalna analiza modalna polegała na pomiarze siły wymuszającej oraz rejestracji odpowiedzi konstrukcji w postaci sygnałów przyśpieszeń w wybranych punktach. Posłużono się metodą SIMO (single input - multiple output), tj. wzbudzenie drgań $\mathrm{w}$ jednym punkcie, $\mathrm{z}$ jednoczesnym pomiarem przyspieszeń $\mathrm{w}$ wielu punktach. W badaniach zastosowano wymuszenie harmoniczne zrealizowane za pomocą wzbudnika modalnego.
\end{abstract}

Słowa kluczowe: eksperymentalna analiza modalna, dźwigar mostowy, dźwigar kompozytowy, pomost kompozytowy, kompozyty FRP

\section{Wprowadzenie}

Badana belka została zaprojektowana jako element nośny do mostu drogowego o rozpiętości teoretycznej w osiach podpór $10,0 \mathrm{~m}$ i całkowitej długości $10,7 \mathrm{~m}$. Belka składa się z dwóch zasadniczych elementów: skrzynkowego dźwigara kompozytowego oraz kompozytowego pomostu. Oba elementy zostały zespolone ze sobą warstwą kleju epoksydowego.

Dźwigar kompozytowy FRP jest niejednorodnym elementem o przekroju skrzynkowym. Dźwigar tworzą pasy górne, dwa środniki i pas dolny. Elementy składowe dźwigara zostały wykonane $\mathrm{z}$ wielu warstw tkanin szklanych o różnej gramaturze i o różnej orientacji włókien. Panel pomostu został wykonany jako warstwowy typu ,sandwich”, na który składają się wielowarstowowe laminaty zewnętrzne oraz wewnętrzna pianka poliuretanowa. Dźwigar został usztywniony

\footnotetext{
1 Autor do korespondencji / corresponding author: Grzegorz Piątkowski, Politechnika Rzeszowska, Katedra Mechaniki Konstrukcji, ul. Poznańska 2, 35-959 Rzeszów; tel. 178651323; pgrzes@ prz.edu.pl

${ }^{2}$ Leonard Ziemiański, Politechnika Rzeszowska, Katedra Mechaniki Konstrukcji, ul. Poznańska 2, 35-959 Rzeszów; tel. 178651327; ziele@ prz.edu.pl
} 
przeponami wewnętrznymi. Dwie z tych przepon były w miejscach oparcia belki na łożyskach. Dwie kolejne to przepony zamykające przekrój skrzynkowy.

Rys. 1. przedstawia kształt i wymiary przekroju poprzecznego badanego dźwigara FRP zespolonego z pomostem kompozytowym, jak również przekrój uproszczonego modelu geometrycznego użytego do badań modalnych.
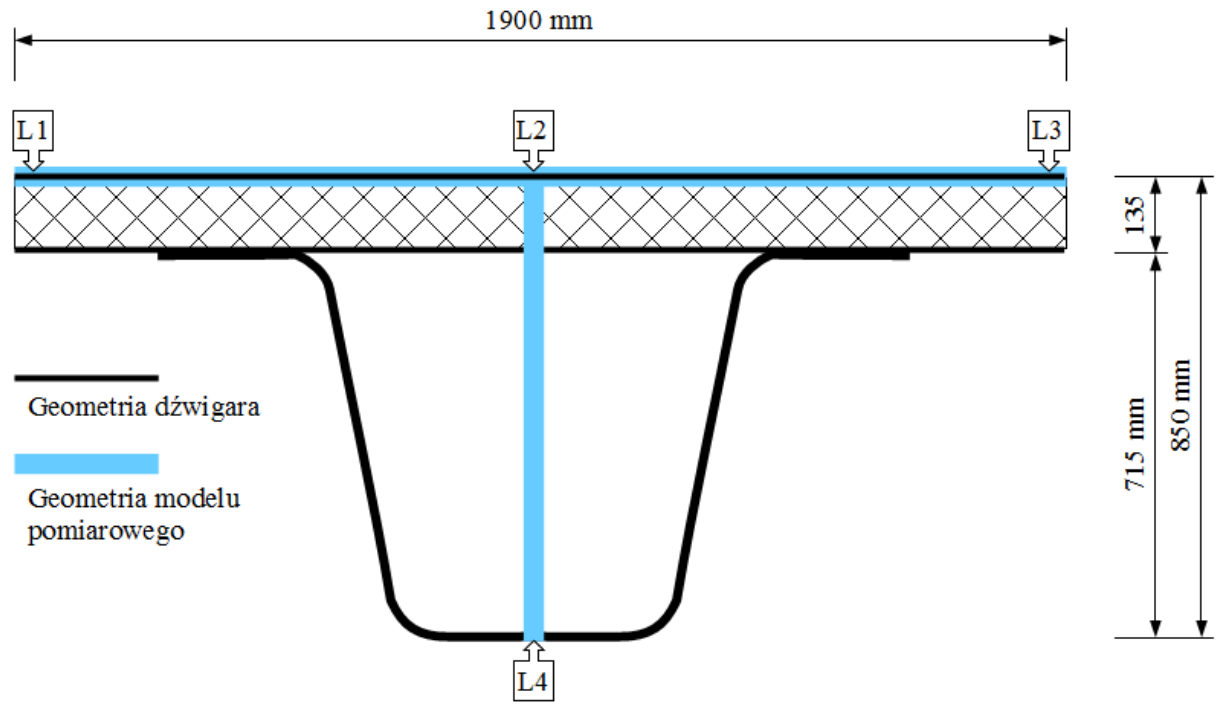

Rys. 1. Przekrój poprzeczny badanego dźwigara

Fig. 1. Cross-section of the test girder

\section{Opis badań}

Podstawowy program badań dynamicznych był realizowany przed realizacją badań statyczno-wytrzymałościowych, gdyż miał na celu ustalenie początkowych charakterystyk dynamicznych testowanej belki.

W badaniach posłużono się techniką SIMO (Single Input - Multiple Output) jako jedną z metod realizowania eksperymentalnej analizy modalnej. W metodzie SIMO poprzez zastosowanie wzbudnika elektrodynamicznego jako generatora sygnału wejściowego (Single Input) możliwy jest jednoczesny pomiar przyspieszeń w wielu punktach pomiarowych (Multiple Output) rozmieszczonych na badanej strukturze [1].

\subsection{Wymuszenie}

Wymuszenie siłą zmienną w czasie realizowane było za pomocą elektrodynamicznego wzbudnika modalnego . Posłużono się wzbudnikiem firmy ModalShop, model 2100E11. Wzbudnik został umocowany do stanowiska badawczego poprzez cztery linki stalowe. Wzbudnik był sterowany sygnałem napię- 
ciowym bezpośrednio $\mathrm{z}$ analizatora pomiarowego. Stosowano wymuszenie białym szumem losowym generowanym w zakresie $0-64 \mathrm{~Hz}$ lub w zakresie $0-128 \mathrm{~Hz}$.

Wymuszenie realizowane było na kierunku pionowym $\mathrm{Z}$ poprzez cięgno, które z jednej strony zostało umocowane do czujnika siły przytwierdzonego do górnej powierzchni pomostu badanej belki, a z drugiej strony poprzez zacisk zostało połączone $\mathrm{z}$ armaturą wzbudnika. Wzbudnik jest widoczny na rys. 2., natomiast lokalizację punktu wymuszenia pokazano na rys. 3 .
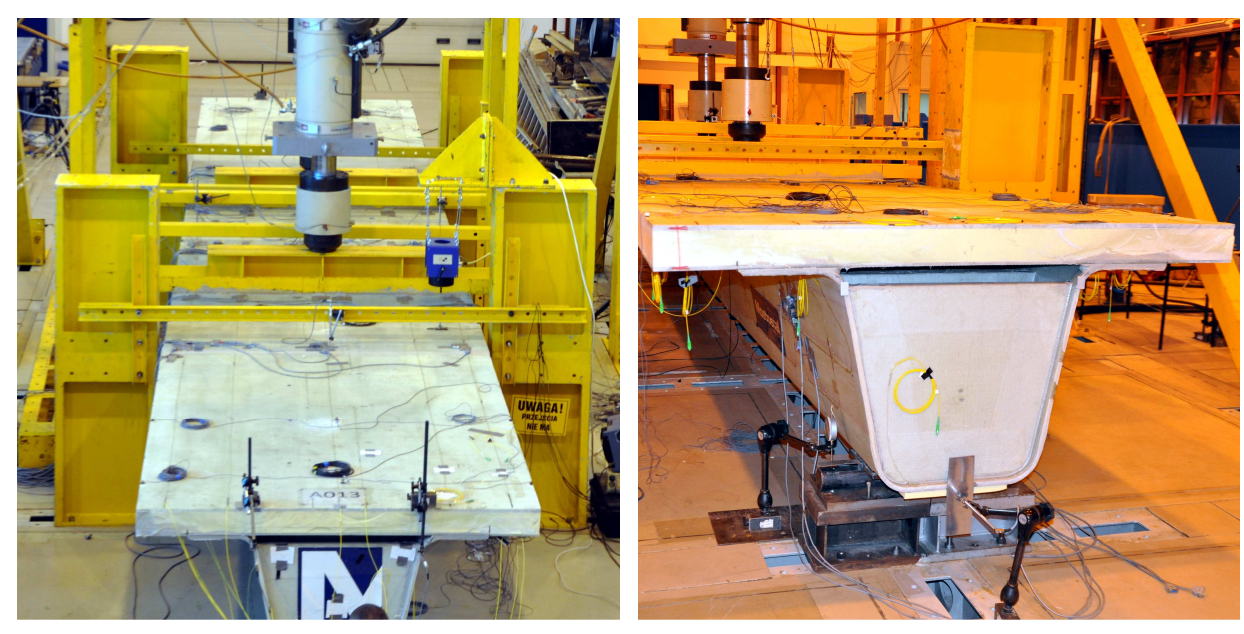

Rys. 2. Stanowisko badawcze do testów statycznych. Wzbudnik modalny

Fig. 2. Research stand for static testing. Modal exciter

\subsection{Pomiar odpowiedzi}

Drgania badanej belki zostały zmierzone poprzez jednoczesną rejestrację przyspieszeń w 28 punktach. Punkty pomiarowe, w których umieszczono akcelerometry piezoelektryczne były rozmieszczone $w$ trzech liniach na górnej powierzchni pomostu (linie L1, L2, L3) oraz wzdłuż jednej linii na dolnej powierzchni pasa dolnego belki (linia L4), co pokazują rys. 1 i rys. 3. Akcelerometry tworzące linie pomiarowe L1 i L3 mierzyły przyspieszenia drgań w kierunku pionowym Z. W punktach leżących wzdłuż linii L2 rejestrowane były sygnały przyspieszeń w dwóch kierunkach, w kierunku poziomym Y i w kierunku Z. Natomiast dla punktów pomiarowych wzdłuż linii L4 rejestrowano drgania w kierunku Y.

W celu dokładnego zobrazowania form drgań stopnie swobody dynamicznej pomiędzy poszczególnymi punktami zostały powiązane ze sobą wzajemnie. 


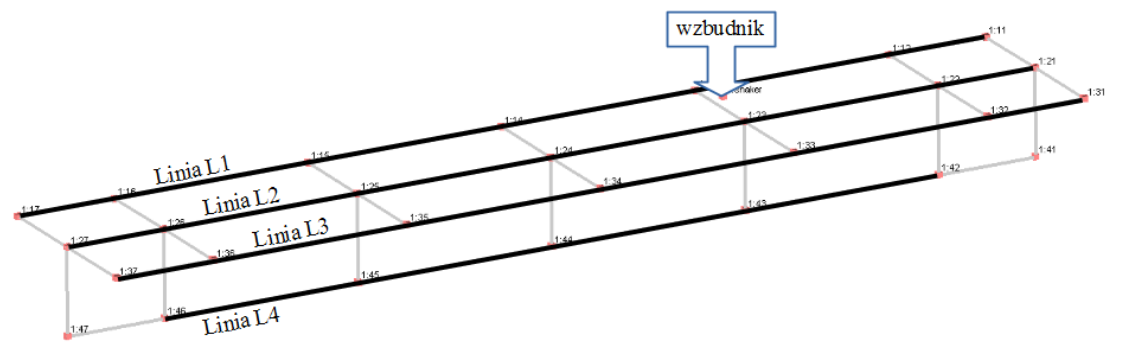

Rys. 3. Rozmieszczenie punktów pomiarowych. Lokalizacja punktu wymuszenia

Fig. 3. Placement of measurement points. Location of excitation point

\section{Wyniki analizy modalnej}

Przeprowadzono eksperymentalną analizę modalną posługując się oprogramowaniem Siemens PLM Software LMS Test.Lab. Zastosowane oprogramowanie rejestrowało sygnały przyspieszeń i jednocześnie obliczało widmowe funkcje przejścia (ang. Frequency Response Function, FRF).

Zastosowano takie nastawy pomiarowe (szerokość pasma wymuszenia, częstotliwość próbkowania), że uzyskano funkcje FRF dla zakresu $0-64 \mathrm{~Hz}$ i w innym wariancie dla zakresu $0-128 \mathrm{~Hz}$, o rozdzielczości częstotliwościowej $0,125 \mathrm{~Hz}$.

Na podstawie funkcji przejścia FRF uzyskano diagramy stabilizacyjne poprzez zastosowanie algorytmu PolyMAX [2]. Z diagramów stabilizacyjnych wybrano do analizy bieguny pokrywające się z charakterystyka widmową na diagramie dla określonych częstotliwości drgań własnych [3].

Nie wszystkie bieguny stabilizacji wskazywane przez algorytm PolyMAX są rzeczywistymi biegunami, część z nich nie występuje w obiekcie rzeczywistym. Dlatego zastosowano również funkcje Mode Indicator Functions (MIFs) jako dodatkowe kryterium. Funkcje MIFs są definiowane w domenie częstotliwościowej i wykazują lokalne minima przy częstotliwościach odpowiadających rzeczywistym postaciom drgań własnych [3].

Doprowadziło to do uzyskania parametrów modelu modalnego w postaci: częstotliwości drgań własnych, współczynników tłumienia i postaci drgań własnych. Otrzymane z analizy pasma $0-64 \mathrm{~Hz}$ częstotliwości oraz współczynniki thumienia zawarte są $\mathrm{w}$ tab. 1. Wykorzystanie funkcji FRF uzyskanych dla pasma $0-128 \mathrm{~Hz}$ dało wyniki zawarte w tab. 2. Częstotliwości przedstawione w tab. $1 \mathrm{i}$ w tab. 2, to zaokrąglone do wielokrotności $0,125 \mathrm{~Hz}$ wyniki uzyskane $\mathrm{z}$ algorytmu PolyMAX. Wyniki przedstawione $\mathrm{w}$ tab. 2, otrzymane $\mathrm{z}$ analizy funkcji FRF w paśmie $0-128 \mathrm{~Hz}$, zostały ograniczone do zakresu $0-64 \mathrm{~Hz}$ celem porównania $\mathrm{z}$ wynikami przedstawionymi w tab. 1. Można zauważyć mi- 
nimalne rozbieżności, wynoszące $0,125 \mathrm{~Hz}$, w określeniu szóstej i siódmej zidentyfikowanej częstotliwości. Są to różnice na poziomie przyjętej dokładności funkcji FRF. Większe różnice względne sięgające 12\% stwierdzono w otrzymanych współczynnikach tłumienia.

Do walidacji zidentyfikowanych form drgań własnych wykorzystano wskaźnik Auto-MAC (Auto Modal Assurance Criterion) [3]. Oczekiwanym wynikiem uzyskanym z analizy współczynnika Auto-MAC są wartości $100 \%$ na przekątnej głównej i jednocześnie wartości $0 \%$ po przekątną. Przyjmuje się, że wartości współczynnika poniżej $60 \%$ wskazują na to, że poszczególne postacie drgań własnych są od siebie niezależne [4]. Macierz obliczonych wartości wskaźnika Auto-MAC zawarta jest w tab. 3.

Tabela 1. Parametry modelu modalnego, pasmo $0-64 \mathrm{~Hz}$

Table 1. Parameters of the modal model, $0-$ $64 \mathrm{~Hz}$ band

\begin{tabular}{|c|c|c|}
\cline { 2 - 3 } \multicolumn{1}{c|}{} & $f_{i}[\mathrm{~Hz}]$ & $\xi[\%]$ \\
\hline 1 & 9,875 & 0,67 \\
\hline 2 & 10,625 & 1,05 \\
\hline 3 & 26,500 & 0,59 \\
\hline 4 & 28,750 & 0,73 \\
\hline 5 & 39,000 & 0,87 \\
\hline 6 & 52,375 & 1,07 \\
\hline 7 & 58,000 & 1,45 \\
\hline
\end{tabular}

Tabela 2. Parametry modelu modalnego, pasmo $0-128 \mathrm{~Hz}$

Table 2. Parameters of the modal model, $0-$ $128 \mathrm{~Hz}$ band

\begin{tabular}{|c|c|c|}
\cline { 2 - 3 } \multicolumn{1}{c|}{} & $f_{i}[\mathrm{~Hz}]$ & $\xi[\%]$ \\
\hline 1 & 9,875 & 0,59 \\
\hline 2 & 10,625 & 1,11 \\
\hline 3 & 26,500 & 0,56 \\
\hline 4 & 28,750 & 0,69 \\
\hline 5 & 39,000 & 0,88 \\
\hline 6 & 52,250 & 1,17 \\
\hline 7 & 57,875 & 1,51 \\
\hline
\end{tabular}

Tabela 3. Kryterium Auto-MAC dla zidentyfikowanych form

Table 3. The Auto-MAC criterion for the identified mode shapes

\begin{tabular}{|r|c|c|c|c|c|c|c|}
\cline { 2 - 8 } \multicolumn{1}{c|}{} & $\boldsymbol{f}_{\boldsymbol{1}}$ & $\boldsymbol{f}_{\mathbf{2}}$ & $\boldsymbol{f}_{\mathbf{3}}$ & $\boldsymbol{f}_{\boldsymbol{4}}$ & $\boldsymbol{f}_{\boldsymbol{5}}$ & $\boldsymbol{f}_{\boldsymbol{6}}$ & $\boldsymbol{f}_{\boldsymbol{7}}$ \\
\hline $\boldsymbol{f}_{\boldsymbol{I}}$ & 100 & 0 & 27 & 0 & 0 & 19 & 0 \\
\hline $\boldsymbol{f}_{\boldsymbol{2}}$ & 0 & 100 & 0 & 0 & 0 & 1 & 0 \\
\hline $\boldsymbol{f}_{\boldsymbol{3}}$ & 27 & 0 & 100 & 0 & 0 & 7 & 0 \\
\hline $\boldsymbol{f}_{\boldsymbol{4}}$ & 0 & 0 & 0 & 100 & 0 & 0 & 1 \\
\hline $\boldsymbol{f}_{\boldsymbol{5}}$ & 0 & 0 & 0 & 0 & 100 & 1 & 0 \\
\cline { 2 - 8 } $\boldsymbol{f}_{\boldsymbol{6}}$ & 19 & 1 & 7 & 0 & 1 & 100 & 4 \\
\hline $\boldsymbol{f}_{\boldsymbol{7}}$ & 0 & 0 & 0 & 1 & 0 & 4 & 100 \\
\hline
\end{tabular}


Zauważalne jest niewielkie sprzężenie pomiędzy pierwszą a trzecią formą. Współczynniki dla pozostałych form wynoszą poniżej $20 \%$.

Forma drgań odpowiadająca pierwszej zidentyfikowanej częstotliwości mająca charakter drgań bryły sztywnej przedstawiona została na rys. 4. Można zauważyć, że belka doznaje rotacji względem osi X, a deformacje są bardzo małe. Taka forma drgań była możliwa ze względu na sposób podparcia belki. Oparcie pasa dolnego dźwigara na dwóch łożyskach stalowych, przesuwnym i nieprzesuwnym, zapewniało swobodę obrotu wokół osi Y. Oparcie belki na wałku łożyska zostało zrealizowane pośrednio przez płytę stalową przyklejoną do kompozytu. W efekcie uzyskano podparcie liniowe z więzami jednostronnymi. Przyjęto, że pierwsza forma drgań przedstawiona na rys. 4 jest konsekwencją braku dokładnego przygotowania powierzchni płyty i wałka łożyska. Forma drgań odpowiadająca drugiej zidentyfikowanej częstotliwości ma charakter drgań giętnych belki swobodnie podpartej. W tej formie dominujące są składowe pionowe, co odpowiada zginaniu w płaszczyźnie XZ. Formę przedstawiono na rys. 5.

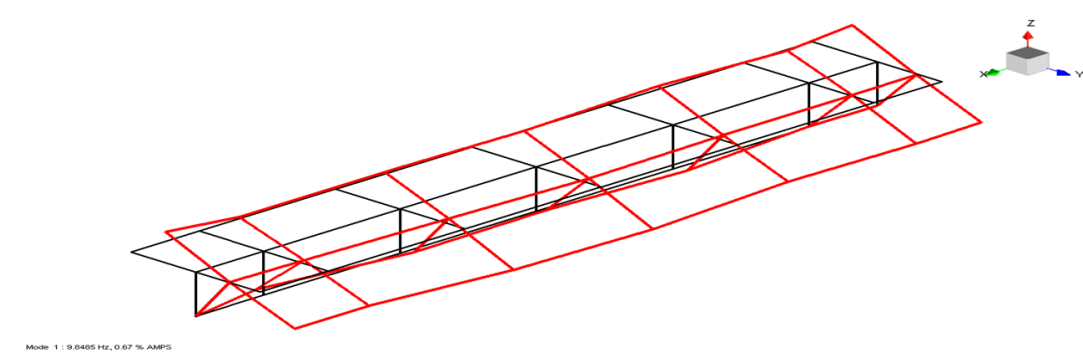

Rys. 4. Pierwsza zidentyfikowana forma drgań

Fig. 4. The first identified mode shape

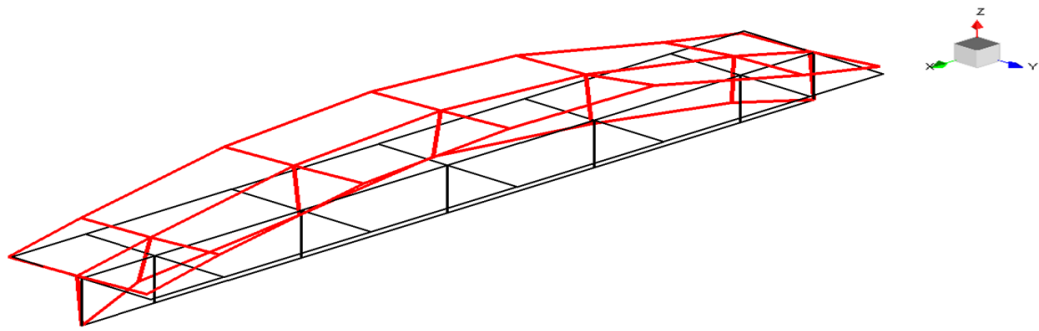

Rys. 5. Druga zidentyfikowana forma drgań

Fig. 5. The second identified mode shape

Kolejna zidentyfikowana forma odpowiadająca $f_{3}$ została przedstawiona na rys. 6. Forma ta wydaje się być formą drgań giętnych w drugiej płaszczyźnie zginania. Formy pierwsza i trzecia są ze sobą sprzężone w $27 \%$ jak wynika to z kryterium Auto-MAC przedstawionego w tab. 3. 


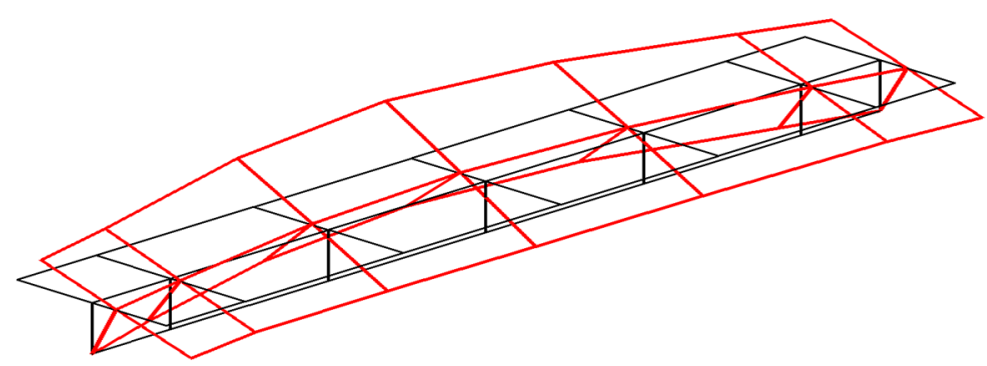

Rys. 6. Trzecia zidentyfikowana forma drgań

Fig. 6. The third identified mode shape

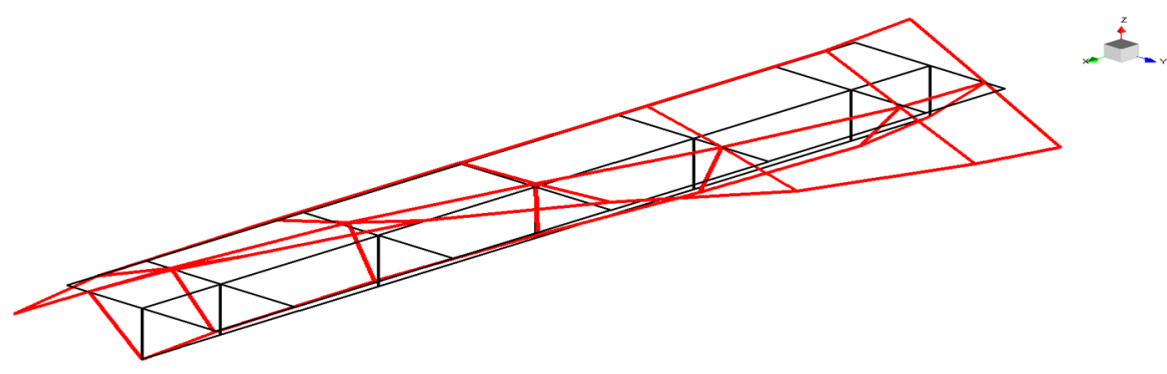

Rys. 7. Czwarta zidentyfikowana forma drgań

Fig. 7. The fourth identified mode shape

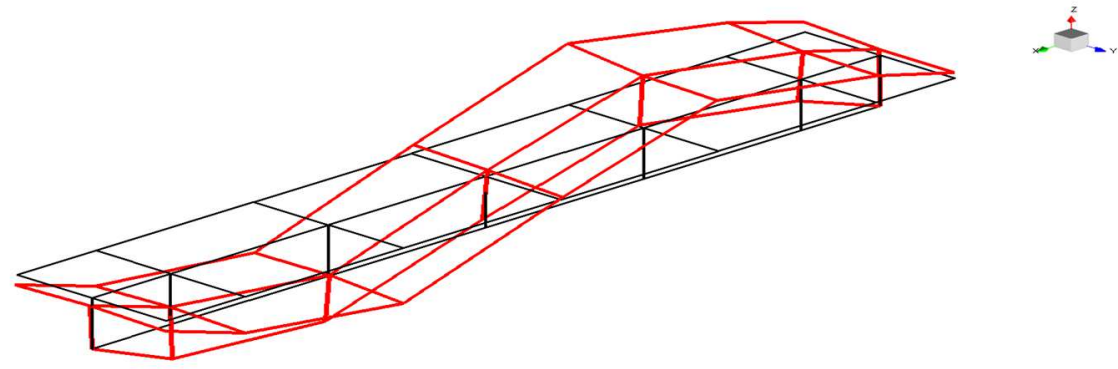

Rys. 8. Piąta zidentyfikowana forma drgań

Fig. 8. The fifth identified mode shape

Czwarta forma odpowiada drganiom skrętnym belki. Forma ta przedstawiona jest na rys. 7. Wyraźnie widoczny jest na środku belki węzeł formy.

Druga forma drgań giętnych w płaszczyźnie XZ to kolejna, piąta zidentyfikowana forma. Położenia węzła widoczne na rys. 8. odpowiada prawie dokładnie połowie rozpiętości belki. 


\section{Uwagi końcowe}

Zastosowana eksperymentalna analiza modalna pozwoliła na zidentyfikowanie podstawowych częstotliwości i form drgań rezonansowych badanej belki kompozytowej. Otrzymane parametry modalne uzyskano stosując algorytm PolyMAX, który pozwolił także na wyznaczenie współczynników tłumienia krytycznego. Wyniki pomiarów wskazują, że w badanym dźwigarze kompozytowym występują sprzężenia pomiędzy niektórymi postaciami drgań (pierwsza, trzecia i szósta postać), które prawdopodobnie wynika z nieidealnych warunków podparcia dźwigara.

\section{Literatura}

[1] Ewins D.J. Modal Testing: Theory, Practice and Application. Research Studies Press Ltd., England, 2000.

[2] Peeters B, Van der Auweraera H, Guillaumeb P., Leuridana J, The PolyMAX frequency-domain method: a new standard for modal parameter estimation?, Shock and Vibration 11 (2004) 395-409.

[3] LMS Test.Lab Modal Analysis User Manual. Siemens Industry Software NV. 2015.

[4] Uhl T. Komputerowo wspomagana identyfikacja modeli konstrukcji mechanicznych. Warszawa: WNT, 1997.

\section{EXPERIMENTAL MODAL ANALYSIS OF A FRP COMPOSITE GIRDER WITH A COMPOSITE DECK PANEL}

\section{S u m m a r y}

The purpose of the study was to estimate modal parameters of the composite girder with a composite deck panel. Experimental modal analysis with a SIMO test was used. Dynamic response of the beam to harmonic excitation was measured with numerous of piezoelectric acceleration sensors. The basic frequencies, vibration modes and damping coefficients were found.

Keywords: experimental modal analysis, bridge girder, composite girder, composite deck panel, FRP composites

Przestano do redakcji: 19.04.2017 r.

Przyjęto do druku: 28.04.2017 r. 